\title{
FORMULASI SEDIAAN LOTION TABIR SURYA EKSTRAK DAUN CEMPEDAK (Artocarpus champeden Spreng)
}

\author{
Restu Harisma Damayanti ${ }^{1, *}$, Lisna Meylina ${ }^{1}$, Rolan Rusli ${ }^{1,2}$ \\ ${ }^{1}$ Laboratorium Penelitian dan Pengembangan Kefarmasian "Farmaka Tropis", \\ Fakultas Farmasi, Universitas Mulawarman, Samarinda, Indonesia \\ ${ }^{2}$ Kelompok Bidang Ilmu Farmasi Klinik dan Komunitas, Fakultas Farmasi, \\ Universitas Mulawarman, Samarinda, Indonesia \\ *Email: restuharisma@gmail.com
}

\begin{abstract}
ABSTRAK
Tabir surya merupakan sediaan kosmetika yang dapat membantu melindungi kulit dari pengaruh buruk sinar matahari. Daun cempedak memiliki aktivitas sebagai tabir surya dan dapat diaplikasikan dalam bentuk lotion. Ekstrak daun cempedak yang diekstraksi dengan n-heksana dan dilanjutkan dengan metanol, diformulasi dalam 3 formula lotion yaitu F1, F2, dan F3. Lotion hasil formulasi dievaluasi berupa pengujian meliputi organoleptis, homogenitas, $\mathrm{pH}$, daya sebar, viskositas, dan pengujian aktivitas tabir surya. Hasil evaluasi menunjukkan bahwa lotion yang diperoleh keduanya memiliki konsistensi setengah padat yang homogen, berbau khas oleum rosae, serta berwarna putih (F1), cokelat $(\mathrm{F} 2)$, cokelat tua (F3). Daya sebar dan $\mathrm{pH}$ lotion berada pada rentang yang sesuai dengan standar sedian lotion. Lotion F2 dan F3 yang mengadung ekstrak daun cempedak memiliki aktivitas tabir surya kategori suntan standar pada penilaian \% Te dan \% Tp dan kategori proteksi maksimal pada penilaian SPF. Pada formula lotion F1 atau basis sediaan, nilai yang diperoleh pada $\%$ Te dan \%Tp serta SPF tidak berada pada rentang penilaian aktivitas sebagai tabir surya atau formula F1 tidak menunjukkan adanya aktivitas sebagai tabir surya.
\end{abstract}

Kata Kunci: tabir surya, daun cempedak, lotion, \%Te dan \% Tp, SPF

DOI: https://doi.org/10.25026/mpc.v6i1.279

\section{PENDAHULUAN}

Spektrum elektromagnetik daerah ultraviolet (UV), yang dibagi menjadi tiga daerah yaitu UVA 320-400 nm, UVB 290$320 \mathrm{~nm}$ dan UVC 200-290 nm. Radiasi UVC disaring oleh atmosfer sebelum mencapai bumi. Radiasi UVB tidak sepenuhnya disaring oleh lapisan lapisan ozon yang dapat menyebabkan kulit terbakar matahari (sunburn), sedangkan radiasi UVA mampu mencapai lapisan epidermis dan dermis lebih dalam, serta dapat memicu penuaan dini pada kulit [1]. Efek berbahaya dari radiasi UV pada kulit dapat dibagi menjadi yaitu efek akut seperti kulit terbakar atau eritema, reaksi fototoksik, fotoalergi dan fotosensitivitas serta efek kronis yaitu fotoaging, kanker kulit dan imunosupresi [2].

Kulit manusia pada dasarnya memiliki perlindungan tersendiri terhadap bahaya sinar UV, yaitu dengan penambahan melanin secara cepat kepermukaan kulit dan pembentukan 
tambahan melanin baru atau pigmentasi kulit. Namun tidak efektif untuk menahan kontak dengan sinar matahari yang berlebih [3]. Oleh karena itu dibutuhkan perlindungan buatan, salah satunya dengan penggunaan tabir surya yang dapat melindungi kulit dari bahaya radiasi sinar [4].

Salah satu tanaman yang berpotensi untuk dimanfaatkan sebagai bahan tabir surya adalah cempedak (Artocarpus champeden Spreng). Daun cempedak sering dimanfaatkan oleh masyarakat Kalimantan di Indonesia secara tradisional sebagai bedak dingin dan penghilang flek hitam pada wajah. Ekstrak kasar daun cempedak pada konsentrasi $350 \mathrm{ppm}$ memiliki aktivitas tabir surya kategori sunblock atau memiliki aktivitas sebagai tabir surya yang baik [5]. Oleh karena itu, agar dapat diaplikasikan, perlu diformulasi dalam bentuk sediaan dengan bahan aktif ekstrak daun cempedak sebagai tabir surya.

\section{METODE PENELITIAN}

\section{Bahan}

Bahan yang digunakan dalam penelitian ini yaitu ekstrak daun cempedak, gliserin, trietanolamin, parafin cair, asam stearat, metil paraben, propil paraben, cera alba, oleum rosae, aquades.

\section{Alat}

Alat yang digunakan dalam penelitian ini yaitu alat gelas, cawan porselin, kaca arloji, toples kaca, batang pengaduk, corong kaca, rotary evaporator, $\mathrm{pH}$ meter, termometer, viskometer, spektrofotometri UV-Vis, timbangan analitik dan wadah lotion.

\section{Prosedur Penelitian}

\section{Pembuatan Ekstrak Etanol Daun Cempedak}

Simplisia daun cempedak yang telah kering dipotong kecil-kecil kemudian diekstraksi dengan metode maserasi dengan menggunakan pelarut $n$ heksana terlebih dahulu. Kemudian residu hasil maserasi diekstraksi kembali dengan pelarut metanol. Proses maserasi ini masing-masing dilakukan selama $3 \times 24$ jam sambil sesekali diaduk. Filtrat yang diperoleh dari hasil maserasi dipekatkan dengan rotary evaporator hingga diperoleh ekstrak kental daun cempedak.

\section{Formulasi Lotion Tabir Surya}

Bahan-bahan dasar lotion ditimbang sesuai dengan komposisi seperti tertera pada Tabel 1. Bahan tersebut dipisahkan menjadi dua bagian yaitu fase air dan fase minyak. Fase minyak yaitu asam stearat, cera alba, dan parafin cair masing-masing dileburkan pada suhu $70^{\circ} \mathrm{C}$. Bahan-bahan yang termasuk fase air seperti gliserin, TEA, metil paraben, propil paraben dan sisa air dicampurkan pada suhu $70{ }^{\circ} \mathrm{C}$ hingga homogen. Kemudian fase minyak dimasukkan sedikit demi sedikit ke dalam fase air pada suhu $70{ }^{\circ} \mathrm{C}$ sambil terus diaduk hingga homogen dan terbentuklah basis lotion. Setelah itu, didiamkan pada suhu kamar hingga suhu $40{ }^{\circ} \mathrm{C}$ dan dimasukkan ekstrak daun cempedak sedikit demi sedikit ke dalam basis lalu terakhir ditambahkan dengan oleum rosae diaduk hingga terbentuk sediaan lotion ekstrak daun cempedak.

\section{Pengujian Sediaan Lotion}

Evaluasi sediaan lotion dilakukan meliputi evaluasi fisik dan evaluasi kimia.

a. Evaluasi Fisik

1) Pengamatan Organoleptis

Diamati sediaan lotion meliputi konsistensi, bau dan warna sediaan lotion.

2) Uji Homogenitas

Dioleskan lotion di atas kaca objek, kemudian ditutup dengan kaca penutup objek lalu diamati kehomogenan lotion. 


\section{3) Pengukuran $\mathrm{pH}$}

Dilakukan kalibrasi $\mathrm{pH}$ meter, dicuci elektroda dan dibilas dengan air suling kemudian dimasukkan ke dalam sediaan lalu ditentukan $\mathrm{pH}$ lotion.

\section{4) Uji Viskositas}

Pengujian ini menggunakan alat viskometer Rheosys Cone and Plate dengan kecepatan $5 \mathrm{rpm}$. Ditimbang sebanyak 0,5 gram sediaan diletakkan pada plate kemudiaan diturunkan cone dan dijalankan alat lalu dibaca nilai viskositas sediaan tersebut.

\section{5) Uji Daya Sebar}

Sediaan seberat 0,5 gram diletakkan di tengah kaca transparan berskala lalu diletakkan kaca transparan lainnya pada bagiaan atas lain lalu didiamkan selama 1 menit lalu dicatat penyebarannya. Tiap tahap ditambah beban seberat 25 gram dan didiamkan selama 1 menit lalu dicatat penyebarannya. Pemberat ditambahkan hingga 125 gram. Penyebaran dicatat melalui 4 sisi.

b. Evaluasi Kimia

1) Uji Efektivitas Sediaan Lotion Tabir Surya

Setiap formula ditimbang 0,25 gram lalu dilarutkan dalam etanol $95 \%$ sampai $25 \mathrm{~mL}$ hingga diperoleh konsentrasi uji 10.000 ppm. Masingmasing larutan diukur serapannya setiap 5 $\mathrm{nm}$ pada rentang panjang gelombang eritema $(292,5-337,5 \mathrm{~nm})$ dan pigmentasi (292,5-372,5 nm) kemudian dihitung \% Te dan \% Tp, serta pada panjang gelombang 290-320 nm kemudian dihitung nilai SPF.

2) Penentuan Kategori Tabir Surya Sediaan Lotion

Penentuan kategori tabir surya berdasarkan tabel kategori penilaian aktivitas bahan tabir surya dilihat dari nilai $\%$ Te dan \% Tp serta SPF .

Tabel 1. Formula Lotion

\begin{tabular}{cccc}
\hline \multirow{2}{*}{ Bahan } & \multicolumn{3}{c}{ Konsentrasi (\%) } \\
\cline { 2 - 4 } & $\mathrm{F} 1$ & $\mathrm{~F} 2$ & $\mathrm{~F} 3$ \\
\hline Ekstrak daun cempedak & - & 2 & 4 \\
Gliserin & 5 & 5 & 5 \\
Trietanolamin & 1 & 1 & 1 \\
Parafin cair & 7 & 7 & 7 \\
Cera alba & 3 & 3 & 3 \\
Asam stearat & 4,5 & 4,5 & 4,5 \\
Metil paraben & 0,2 & 0,2 & 0,2 \\
Propil paraben & 0,03 & 0,03 & 0,03 \\
Oleum rosae & 3 tetes & 3 tetes & 3 tetes \\
Aquades & ad $100 \mathrm{~mL}$ & ad $100 \mathrm{~mL}$ & ad $100 \mathrm{~mL}$ \\
\hline
\end{tabular}

Tabel 2. Evaluasi fisik sediaan lotion

\begin{tabular}{|c|c|c|c|c|c|c|c|}
\hline \multirow{2}{*}{ Formula } & \multicolumn{3}{|c|}{ Organoleptis } & \multirow{2}{*}{ Homogenitas } & \multirow{2}{*}{$\mathrm{pH}$} & \multicolumn{2}{|c|}{ Daya sebar Viskositas } \\
\hline & Warna & $\mathrm{Bau}$ & Konsistensi & & & $(\mathrm{cm})$ & (Pa.s) \\
\hline F1 & Putih & Khas oleum & Setengah padat & Homogen & 7,65 & 7,34 & 6,21 \\
\hline $\mathrm{F} 2$ & Coklat & Khas oleum & Setengah padat & Homogen & 7,43 & 7,30 & 7,03 \\
\hline F3 & Coklat tua & Khas oleum & Setengah padat & Homogen & 6,61 & 6,94 & 7,65 \\
\hline
\end{tabular}


Tabel 3. Evaluasi kimia

\begin{tabular}{ccccccc}
\hline \multirow{2}{*}{ Formula } & \multicolumn{6}{c}{ Aktivitas tabir surya } \\
\cline { 2 - 7 } & $\% \mathrm{Te}$ & Kategori & $\% \mathrm{Tp}$ & Kategori & SPF & Kategori \\
\hline F1 & 87,44 & - & 84,93 & - & 0,65 & - \\
F2 & 11,15 & Suntan standar & 10,63 & Sunblock & 9,05 & Maksimal \\
F3 & 6,83 & Suntan standar & 4,57 & Sunblock & 12,48 & Maksimal \\
\hline
\end{tabular}

\section{HASIL DAN PEMBAHASAN}

Hasil evaluasi fisik dan kimia sediaan lotion ekstrak daun cempedak dapat dilihat pada tabel 2 dan tabel 3 .

Penelitian ini menggunakan ekstrak daun cempedak sebagai zat aktif dalam pembuatan lotion sebagai tabir surya. Tanaman cempedak mengadung metabolit sekunder berupa senyawa golongan flavonoid [7] yang dapat berpotensi sebagai tabir surya karena memiliki gugus kromofor yang mampu menyerap sinar UV baik UV A maupun UV sehingga dapat menggurangi atau menghambat UV masuk kekulit [8].

Penelitian ini menggunakan 3 variasi konsentrasi untuk membandingkan aktivitas tabir surya masing-masing sediaan dengan metode penentuan persentase eritema dan persentase pigmentasi serta metode penentuan nilai SPF. Hasil evaluasi fisik sediaan lotion pada pengamatan organoleptis F1, F2, dan F3 menunjukkan sediaan berwarna putih, coklat, dan coklat tua. Ketiga formula beraroma khas oleum rosae serta konsistensi setengah padat. Pada pengujian homogenitas ketiga formula menujukkan sediaan yang homogen. Uji homogenitas bertujuan untuk mengetahui ketercampuran masing-masing bahan dalam sediaan. Syarat sediaan lotion yaitu jika dioleskan pada sekeping kaca tidak menunjukan adanya bintik-bintik atau butiran kasar antara komponen penyusun pada lotion [9]. Homogenitas suatu sediaan berpengaruh terhadap efektivitas terapi karena berhubungan dengan kadar obat yang sama pada setiap pemakaian. Jika sediaan telah homogen maka diasumsikan pada saat pemakaian atau pengambilan kadar zat aktif akan selalu sama [10].
Pengukuran $\mathrm{pH}$ sediaan bertujuan untuk menghindari terjadinya iritasi pada kulit. Menurut SNI 16-4399-1996 persyaratan $\mathrm{pH}$ sediaan topikal yaitu antara $\mathrm{pH}$ 4,5-8,0. Hasil pengujian $\mathrm{pH}$ menjukkan $\mathrm{F} 1, \mathrm{~F} 2$, dan $\mathrm{F} 3$ berada pada $\mathrm{pH}$ 7,$65 ; 7,43$; dan 6,61. Dengan demikian dapat diprediksi ekstrak yang ditambahkan pada sediaan bersifat asam karena semakin banyak ekstrak yang ditambahkan (F1 tanpa ekstrak, F2 ekstrak 2\% dan F3 ekstrak 4\% ) menyebabkan menurunya nilai $\mathrm{pH}$ pada sediaan tersebut. Kesesuaian $\mathrm{pH}$ kulit dengan $\mathrm{pH}$ sediaan topikal mempengaruhi penerimaan kulit terhadap sediaan. Kemungkinan iritasi kulit akan sangat besar apabila sediaan terlalu asam atau terlalu basa [11]. Pengujian viskositas bertujuan untuk mengetahui adanya perubahan kekentalan pada tiap formula [11]. Hasil pengujian viskositas pada F1, F2 dan F3 yaitu 6,21; 7,03; dan 7,65. Hal ini membuktikan semakin besar konsentrasi ekstrak yang ditambahkan maka semakin besar pula viskositasnya. Pengujian daya sebar betujuan untuk mengetahui kecepatan penyebaran lotion saat dioleskan pada kulit [12]. Hasil pengujian daya sebar menunjukkan perbedaan penyebaran masing-masing formula (F1, F2 dan F3) yaitu 7,34; 7,30; dan 6,94. Hal ini disebabkan karena adanya perbedaan viskositas dari masing-masing sediaan dimana daya sebar berbanding terbalik dengan viskositas. Semakin tinggi viskositas sediaan maka semakin kecil daya sebarnya.

Evaluasi kimia sediaan lotion bertujuan untuk membandingkan aktivitas tabir surya dari sediaan yang ditambahkan ekstrak dengan konsetrasi yang berbeda 
yang dilakukan pengujian meliputi penentuan persentase transmisi eritema (\% Te), presentase transmisi pigmentasi (\%Tp), dan penentuan nilai SPF.. Hasil pengujian dan perhitungan nilai \%Te dan \%Tp serta SPF pada F1, F2, dan F3 yaitu pada F1 menujukkan nilai \%Te dan \%Tp yang paling besar serta nilai SPF menujukkan nilai yang paling kecil sedangkan pada F3 memiliki nilai \%Te dan \%Tp yang paling kecil serta nilai SPF yang besar. Hal ini menujukkan semakin kecil nilai $\%$ Te dan \%Tp maka semakin efektif pula senyawa tersebut menyerap UV sebaliknya semakin besar nilai SPF maka semakin efektif pula senyawa tersebut menyerap UV. Hal ini dikarenakan pada lotion F3 konsetrasi ekstrak yang ditambahkan lebih banyak dibanding F1 dan F2 sehingga kadungan ekstrak yang berpotensi sebagai tabir surya lebih banyak dalam sediaan sehingga F3 lebih efektif dalam menyerap sinar UV. Hal ini menunjukkan semakin besar konsentrasi ekstrak yang digunakan maka semakin baik pula aktivitasnya sebagai tabir surya.

\section{KESIMPULAN}

1. Daun cempedak dapat diformulasikan menjadi sediaan lotion

2. Evaluasi fisika dan kimia sediaan lotion sesuai dengan standar SNI dan stabil

3. Lotion ekstrak daun cempedak memiliki aktivitas sebagai tabir surya

\section{DAFTAR PUSTAKA}

[1] Dutra, E.A., et al. 2004 Determination of Sun Protection Factor $(S P F)$ of Sunscreen by UV Spectrophotometry. Brazilian Journal of Pharmaceutical Sciences. 40(3): 381-385.

[2] Balakhrisnan, K., \& Narayanaswamy. 2011. Botanicals as Sunscreens: Their Role in the Prevention of Photoaging and Skin Cancer. International Journal of Research in Cosmetics Science. 1(1): 1-12.
[3] Departemen Kesehatan Republik Indonesia. 1985. Formularium Kosmetika Indonesia. Direktorat Jenderal Pengawasan Obat dan Makanan. Jakarta.

[4] Wang, S.Q., Stanfield, M.S., Osterwalder, U. 2008. In Vitro Assessment of UV A Protection by Populer Sunscreen Available in the United States. JournalAmerican Dermatoloy. 59. 934-942

[5] Whenny, Rolan Rusli, Laode Rijai. 2015. Aktivitas Tabir Surya Ekstrak Daun Cempedak (Artocarpus champeden Spreng). Jurnal Sains dan Kesehatan.1. (4).

[6] Balsam, M.S., \& Sagarin, E. (Eds). 1972. Cosmetics : Science and Technology 2nd Ed, Vols 1-3. Interscience Publishers, inc. New York.

[7] Rahmawati, Dwi. 2012. Kandungan Metabolit Sekunder dan Aktivitas Antioksidan Daun Cempedak dan Kulit Batang Cempedak (Artocarpus champeden Spreng). Skripsi Fakultas Farmasi Universitas Mulawarman. Samarinda.

[8] Shovyana, H.H and Zulkarnain, A. Karim. 2013. Stabilitas Fisik dan Aktivitas Krim W/O Ekstrak Etanolik Buah Mahkota Dewa (Phaleria Macrocarpha (Scheff.) Boerl,) Sebagai Tabir Surya. Traditional Medicine Journal. 18. (2). 109-117.

[9] Rahayu, S. 2016. Hubungan Perbedaan Konsentrasi Ekstrak Kunyit Putih (Curcuma manga Val) terhadap Sifat Fisik Lotion. Prosiding Rakernas dan Pertemuan Ilmiah Tahunan Ikatan Apoteker Indonesia 2016. ISSN: 2541-0474.

[10] Swastika, A., dan Mufrod Purwanto. 2013. Aktivitas Antioksidan Krim Ekstrak Sari Tomat (Solanum lycopersicum L.). Traditional Medicine Journal. 18(3). 
[11] Ulaen, S.P., Suatan Y.S., dan Ririn, A. 2012. Pembuatan Salep Anti Jerawat dari Ekstrak Rimpang Temulawak (Curcuma xanthorrhiza Roxb.). Jurnal Ilmiah Farmasi. 3(2): 45-49.
[12] Latifah, F., Sugihartini, N., Yuwono, T. 2016. Evaluasi Sifat Fisik dan Daya Iritasi Sediaan Lotion Minyak Atsiri Bunga Cengkeh (Syziqium aromaticum) dengan Berbagai Variasi Konsentrasi. Traditional Medicine Journal. Vol. 21 (1), p 1-5. 